\title{
Overcoming the efficiency gap: energy management as a means for overcoming barriers to energy efficiency, empirical support in the case of Austrian large firms
}

\author{
Christian Schützenhofer (D)
}

Received: 5 May 2020 / Accepted: 12 April 2021 / Published online: 19 May 2021

(C) The Author(s) 2021

\begin{abstract}
The energy efficiency gap has been presented as a prevalent paradox in the literature as individuals and firms fail to invest money or effort in seemingly highly profitable efficiency improvements. This article contributes to answering which management tools promote the realization of economic energy savings. This article first provides a comparison of the barriers to energy efficiency in firms from the literature with the prescriptions of ISO standards for energy management. Second, we provide empirical evidence that such ISO-certified large Austrian firms increased implementation of energy efficiency measures by $165 \%$ compared to those firms with business-as-usual decision-making methods. These higher conservation efforts observed support the hypothesis that ISO standards are an effective instrument to overcome efficiency barriers in an economic way. The main contributing factors for this achievement are the internalization of the identification process of savings potentials and setting up a stringent decision-making and governance process, thereby increasing implementation rates of measures.
\end{abstract}

This article contributes to existing literature by presenting a method to overcome the efficiency gap in firms and provides evidence for this method's practicality and effectiveness.

C. Schützenhofer $(\bowtie)$

University of Vienna, Oskar Morgenstern Platz 1, Vienna, Austria e-mail: a0625090@univie.ac.at

e-mail: schuetzenhofer@gmx.at
Keywords Energy efficiency gap •

Barriers to energy efficiency · Management system · ISO $50001 \cdot$ ISO $14001 \cdot$ Energy efficiency directive . Behavioural energy efficiency

\section{Introduction}

The utilization of (carbon-based) energy sources for various, previously manual tasks and transportation has brought an enormous increase in welfare to many. However, the fossil sources tapped have been shown to be unsustainable by the International Panel on Climate Change (Pachauri et al., 2014). At the same time, it is generally assumed that rational, rent-seeking agents invest in energy-efficient machinery if it is deemed economic, considering risks and uncertainties. However, literature provides plenty of documented, forgone chances to economically improve energy efficiency, as summarized by Jaffe and Stavins (1994); reviewed by Sorrell et al. (2011), Schulze et al. (2016) and Schleich (2009); described for Germany by Schleich (2009), by Trianni and Cagno (2012), Trianni et al. (2016) for Italy; and by Chan and Kantamaneni (2015) for Singapore. A comprehensive presentation of these non-realized economic savings potentials is given by Sorrell et al. (2004). This phenomenon of non-commitment in apparently economic opportunities was dubbed energy efficiency gap by Hirst and Brown (1990). This energy efficiency gap is estimated to amount to substantial monetary (USD 1.2tr. alone in the USA) and energy savings ( $23 \%$ end use energy in the USA, as estimated 
by Granade et al. (2007)). It poses a paradoxical situation and is taken for an indication of maladapted behaviour or market failures in the literature by Jaffe et al. (2004). Subsequent studies point to organizational effects being central to the efficiency gap in firms: Cooremans (2011) and Cooremans (2012) argue that managerial and organizational barriers outweigh economic and market barriers, as strategic aspects of energy efficiency are prioritized over profitability. Johansson (2015) states that the organizational implementation of the energy management process is crucial, especially in terms of power of the energy manager and for lowering informational barriers. Mahapatra et al. (2018) highlight the powerful effect of behavioural changes in the work force in heavy industry. Lawrence et al. (2019) identify organizational effects in firms as most hindering barriers. Backlund et al. ( 2012b) suggested extending the term efficiency gap to contain organizational energy efficiency measures (EEMs) to capture their effect in the overall potential. A further extension to the efficiency gap, the 'energy management gap' representing the additional conservation achievable with better energy management, was shown to be significant by Paramonova et al. (2015). This article follows these authors' lead in highlighting an organizational method to overcome these barriers and supports it with empirical evidence. The findings are summarized as Hypotheses in this section below.

To overcome the energy efficiency barriers induced by market failure effects, several policy measures have been proposed and implemented (Sorrell et al., 2011). Drivers for implementing EEMs have been proposed and reviewed by Thollander and Ottosson (2008) and Trianni et al. (2017). Their effectiveness and efficiency have been analysed by Rietbergen et al. (2002) and Redmond and Walker (2016). However, Jaffe and Stavins (1994) show that of these implemented policy measures, most (such as technical standards and subsidies) are only second best in welfare economic terms. Taxes can be a first best option to reduce externalities by incentivizing investment in energy-efficient technology, as shown in Wirl (1997) and discussed by Howarth and Andersson (1993). One instrument to overcome informational barriers, implemented by the European Union from 2009 on, are prescribed energy efficiency audits. These have been shown to be cost-effective by Fleiter et al. (2012) and Paramonova and Thollander (2016). However, these energy audits' effectiveness in terms of highlighting the full energy efficiency potential is left unassessed. Therefore, one can say that not many effective and efficient tools are established to stipulate energy efficiency in firms and therefore welfare.

One of these very few welfare-efficient instruments to overcome the efficiency gap has been proposed by Backlund et al. (2012a, 2012b) and Fawcett et al. (2019) as good energy management practices such as those prescribed in ISO 50001 (ISO, 2011) and ISO 14001 (ISO, 2015). These management frameworks have been shown to generate in aggregate $1 \%$ to $1.6 \%$ of additional savings by Rietbergen et al. (2017). Anderson and Newell (2004) find that within government-sponsored energy audits focusing on low-hanging fruits, firms implemented about half of the recommended measures. However, no control group data has been available in these studies, preventing the additionality effect of these audits to be accounted for. Energy service contracts may also lower barriers, but have been reported to have limited applicability mainly due to transaction costs (Nolden and Sorrell, 2016). The study that comes closest to our work is that of Schleich (2009) who investigates barriers for the German industry in survey data and concludes that most barriers are significant. However, the study is limited in two respects: it does not include whether measures are cost efficient for the individual organizations, or which measures were implemented and the subsequent realized energy savings. In this article, we provide a representative sample of large Austrian firms providing evidence for the effectiveness of such management systems.

We follow Jaffe and Stavins (1994) who define 'energy efficiency' to mean energy services provided per unit of energy input (e.g. litres of water heated to a specified temperature per cubic meter of natural gas input). A barrier for energy efficiency, as defined by Sorrell et al. (2011), is 'a postulated mechanism that inhibits investments in technologies that are both energy efficient and apparently economically efficient'. By the term efficiency gap, posed by Gerarden et al. (2015), we mean the general phenomenon that not all such measures are implemented, which might be caused by market barriers. We follow Jaffe and Stavins (1995) in categorizing these barriers as economic, behavioural and organizational.

Management systems (henceforth abbreviated as 'MS') provide what can be summarized as frameworks for 'good management practice' by stipulating a stringent set of policies and organizational processes in order to ensure a 'continuous improvement cycle'. In the case 
of energy management in firms (Lawrence et al., 2019), such a management system is provided for example by the standard ISO 50001 (ISO, 2011). We follow Jaffe et al. (2004) that resistance to change (equipment or behaviour) can be rational due to the non-negligible risk of impairment of product quality or production flow. Even more significant is that possible failures of new equipment (implemented as EEM) can bear such high penalties to the decision-maker that, although the probability might be low, efficiency opportunities are not followed. Whether this barrier stems from rational risk assessment and uncertainty, or maladapted decisionmaking shall not be discussed here.

Our claim is that by having an energy management system in place, these barriers and several others can be substantially lowered. Hypothesis 1 summarizes these arguments:

Hypothesis 1: Barriers to energy efficiency are lowered by energy and environmental management systems, and therefore more savings measures are implemented in those firms with such systems in place when compared against those employing usual management practices.

In the context of this article, 'usual management practice' implies all other practices of decision-making related to energy efficiency projects. In our control group, these were represented by those firms not having implemented management systems according to EN ISO 50001 or EN ISO 14001 and deciding on energy investments in their traditional way.

The non-implementation of apparently economic EEMs may originate from a lack of information on the decision-making process: information on the risk of failure or performance of a new and technically different (but more efficient) technology is naturally limited. These barriers can be regarded as perceived risk in contrast to the usual uncertainty (about certain aspects of performance of the technology) which can be quantified and therefore incorporated in investment decisions (Sutherland, 1991). This distinction is crucial since the potential loss from the involved risk can be much higher (orders of magnitude, we found) than those from an uncertain performance, say not meeting the expected energy efficiency benchmark. Specifically, production halts or product recalls were reported as concerning, possibly due to new equipment being inappropriate or malfunctioning due to 'unforeseeable' reasons. The inherent risk of a new technology therefore can render the whole EEM uneconomic. Moreover, testing equipment in order to 'convert' this risk to measurable uncertainty is not only costly, but by the nature of the uniqueness of most production processes (e.g. a new, efficiently regulated pump as part of a specialized production line), this testing can only be done in house, posing opportunity costs for personnel as described by Jaffe et al. (2004). In the commercial and industrial sectors, case studies and survey evidence provide the bulk of the empirical evidence (Concepción López Fernández and Serrano-Bedia, 2007), with firms indicating that production disruptions and inconvenience can preclude investment in energy efficiency (EU, 2014) (Schleich, 2009). These barriers hint at various unmeasured costs, project risks and uncertainty that are unlikely to be well quantified in estimated implementation costs and projected annual savings. Examples thereof are provided by Simader (2017). These barriers have been introduced in the cited literature but have, to the best of the author's knowledge, not been represented in empirical data in an independently quantified and then firm-reviewed manner. This article fills this gap.

Reducing performance uncertainty in many cases cannot be achieved by gathering information from the market or original equipment manufacturers, but often has to be obtained by testing the new technology in the given production process, hence involving several units of an organization. Moreover, it necessitates stringent organizational processes in terms of specialization, formalization and centralization which can be provided by a management system (Concepción López Fernández and Serrano-Bedia, 2007). As an example, we give the extreme case of a pharmaceutically certified production line ('qualified' in Good Manufacturing Practice parlance): by this pharmaceutical standard, it is certified as it is-including all peripheral supply appliances at the time of certification. Any change requires (potentially) a recertification of the whole line (including several test runs and quality checks and the corresponding meticulous documentation, taking weeks up to months). This extends as far as to replacements of minor parts of production, e.g. pump drives. This example certainly is an extreme case but demonstrates the principle that implementing EEMs includes several organizational parts of a firm to work together in a complex way.

These barriers increase upfront costs which reduces adoption likelihood even further due to maladapted decision-making, as Decanio (1998) identified. Taking 
the effort and costs of testing into account, to an outside observer or technical auditor, apparently economic measures can become uneconomic. Hence, we doubt the seemingly large potential identified by external observers comparing technology standards such as in Granade et al. (2007).

We argue that management systems can reduce these costs of information acquisition significantly, thereby reducing the organizational barriers mentioned in the last paragraph: By providing for the firm-internal communication channels, management systems can reduce perceived risks by transferring the costs of information acquisition (e.g. testing) to the responsible (research) department. Thereby, synergies can be realized and the costs are not perceived as additional implementation costs, count as process R\&D. Thereby, we expect availability-biased and base rate-neglected decisionmaking to be reduced. We specify these arguments in Hypothesis 2:

Hypothesis 2: Whether or not proposed measures are implemented depends highly on the perceived risk and the management style.

We specify the arguments above concerning the economic viability of MS in firms in Hypothesis 3:

Hypothesis 3: Energy and environmental management systems are a profitable means of implementing organizational processes in firms in order to get economic energy efficiency measures implemented.

In order to test these hypotheses, data was gathered in 2015 and 2016 of firms which performed energy efficiency audits either internal or external. This process was initiated by the European Union Energy Efficiency Directive (Directive 2012/27/EU). It prescribes all member states to have all large firms perform technical energy efficiency audits in order to highlight energy efficiency improvement measures, henceforth referred to as 'audits'. National implementations vary. In most states, firms had the options of having (accredited) external auditors performing these audits, or if they had an ISO 50001- or ISO 14001-certified management process in place, working out measures by their own staff. That is, a firm reached compliance by either an external service provider or by certifying the internal process for EEM implementation. For compliance to the law, the incentives to implement management systems can be regarded as limited since the costs of these exceed those of audits by a factor of 3 to 6 due to the much wider scope of MS. These costs were obtained in this study in the form of invoices and budgets which cannot be disclosed. In the longer perspective, the benefits of MS outweigh the higher costs as we will show below. Also, MS are highly economic as the efficiency increase they induce covers the upfront costs in less than the 4-year EU-EED audit period.

In the remainder of this article, we present the applied methodology in the 'Methodology' section, followed by the dataset and its background in the 'Empirical data' section. In the 'Results and discussion' section, we interpret the data and provide support for the hypotheses. The 'Conclusions' section concludes with the discussion and outlook.

\section{Methodology}

Data on all 2200 Austrian firms which had to perform an audit or have a MS in place was gathered by the 'Monitoringstelle Energieeffizienz', a private agency contracted by the Austrian government for supervising progress on the EU's policy. However, the quality of the data does not allow its use for our purposes here as the chosen mode for compliance (audit or MS) cannot be matched to firms' savings in the agency's database. We investigated all EU countries' energy efficiency directives implementation mechanisms. No other EU country collected relevant data centrally, but all had different authorities perform random compliance checks. Hence, the dataset we collected for this study is unique. Other ecological-driven policies distort the statistics in some countries. For example in Germany, energy tax refundability depends on having an energy MS in place, thereby providing a strong incentive (energy MS adoption is high in Germany). To our purpose, we matched two datasets: the identified potential from the external or internal energy audits and the energy savings from implemented measures in the 2 years after these audits. Control variables such as industry type (via NACE code), total energy consumption, energy intensity and revenue were collected in the sample (see Appendix Table 7).

We chose a bottom-up approach for gathering the data. For the control group (employing business-asusual energy management), the efficiency potential 
was identified via external energy audits performed by officially accredited energy auditors (one of them is the author of this article). Audits had to follow the EN 16247 (1) technical energy auditing standard and its respective parts for production, buildings or transport energy consumption, and the Austrian energy efficiency law implementing the EU energy efficiency directive. The efficiency potential was divided into three categories: production-, transport- and building-related savings potentials. Audit results were standardized in reporting, technical identification, description, calculation of measures' (potential) savings and form of presentation to the firms. Therefore, communication, documentation and workflow were diligent and standardized for the whole sample. Firms' management level to whom the audit results (energy flow analysis and potential EEMs) were presented was the firms' choice.

This audit modus ensured much more robust and reliable results than a top-down, technology-wise assessment as presented by e.g. Solnørdal and Foss (2018). Economic feasibility was assessed by the auditors for each identified measure and each underwent a quantitative costs and savings analysis. A crucial aspect was the risk of production disruption or of possible product quality impairment as a result of implementing an EEM. Related to that, a rating was given for each EEMs' organizational implementation-effort and risk on a point scale from 0 to 1 . The exact rating methodology is given in Appendix 1. This thorough investigation included an expert opinion on quantifying the savings in kilowatt-hours through technical assessments based on measurements and energy flow analysis. Implementation costs, including firm-internal ones such as personnel costs from organizing the change, were estimated by the same experts together with the firms' counterparts. Organizational or processrelevant changes were assessed for each EEM on a point scale from 0 (substantial changes) to 1 (minor ones). This collection of implemented EEMs followed the requirements by Austrian law for white energy efficiency certificates (Adensam et al., 2013). A major problem in top-down studies is that (often small) efficiency improvements are superimposed by (often much larger) production volume changes and other covariates. The two major biases in this regard are production volume and seasonal weather fluctuations. Both were controlled for by normalizing to a base line or standard year in terms of individual production volume, or heating degree days in the respective area of the sites. For establishing that the means of the three groups were significantly different from each other, we compared them pairwise with a standard $t$-test. Correlation factors between all variables were calculated in order to relate our sample to theory and identify possible further effects. The correlation matrix is provided in the 'Empirical data' section in Table 2. For assigning the observed variations of the effect (EEM implementation rate) to control parameters, an analysis of variance (ANOVA) is presented in the Appendix in Table 5.

As an example of the involved complexity, the treatment of compact fluorescent light bulbs as interchangeable with other forms of lighting, as performed by Granade et al. (2007), is given here. Treating these light sources as interchangeable ignores the different light spectra and thereby the risk of adverse utility changes. Quantifying this aspect is difficult and highly depends on the application. Then again, non-energy-related benefits such as improved process flow or quality can increase EEMs profitability (Rasmussen, 2017). But in the case of compact fluorescent light bulbs, their mercury content and additional disposal costs were neglected as a detrimental factor in the mentioned study. We incorporated these secondary factors (both positive and negative) in our analysis in the variable 'organizational effort' or the implementation costs when assessing the EEMs (Appendix Table 4). This assessment was cross-checked by firms' technical staff. All EEMs' aspects were included in presentations in front of plant managers, thereby providing incentives for the external and internal auditors to apply due diligence in these assessments. These presentations were the first step in budget allocation and created awareness of the savings potential with the management. These presentations were the same in content and style for both groups of firms. Implementation difficulty, performance uncertainty and risk factors of each EEM were aggregated on firm level. Nominally, these barriers were positively framed as 'project maturity' (in the German original: 'Ausgereiftheit der Überlegungen'), and summarized on a point scale from 0 (high risk or effort) to 1 (low risk, uncertainty or effort). Points were given as follows: 0 for a plain idea, 0.5 if an idea was firm-internally 
conceived and cross-checked and 1 point for a readily worked out measure awaiting implementation. Only economic and viable measures (by this grading) qualified for consideration as part of a firm's aggregated efficiency potential. Economic viability was judged by comparing the measures' ROI with the firms' stated threshold rate for investments. The minimum ROI considered was $4 \%$ per annum, exceeding the respective firms' cost of capital, and therefore can be deemed profitable. In the MS group, measures partly came from the firms' documentation, additional to the auditors' results, and were all assessed as described above. The quality of the assessment of the measures can be regarded as similar between the groups. The identified effects can therefore be attributed to the decision-making and management process as the technical, organizational and economic barriers were carefully incorporated in the assessments of measures. Measures below $1 \mathrm{MWh}$ annual savings are not part of our sample due to the costs of the certification process, and the low market price of the certificates (2015 average price was $65 € / \mathrm{MWh}$ (Schuch and Simader, 2017)). This absence as well as such small measures' frequency is symmetrical for both the MS and the control group (Table 1). The data is complete insofar as the auditors were exclusively in charge for each firm, thereby avoiding selection bias.

The data from the audits in terms of energy efficiency potential and the white certificates in terms of implemented EEMs were gathered from May 2014 to March 2016 and encompassed 121 firms out of which 51 complete datasets could be extracted. Together with firm-specific aspects such as industry, revenue and type of management systems in place, one database was compiled (see Appendix 2 for the data). Great care was taken in order to only include measures implemented after a firm did an audit or implemented a management system in order to allow the inference of a causal relationship. Double counting and seasonal effects can be excluded by the extended methodology prescribed by the Austrian state for issuing these white certificates (Adensam et al., 2013). The dataset is cross-sectional in manufacturing, services and construction industries. The whole dataset has been collected by the auditors themselves. The selection of firms is based on their number of employees and revenue, focusing on 'large' firms by the definition of the EU (revenue $>50 \mathrm{M} €,>249$ employees by headcount). Out of a total of 2200 such qualifying and legally obliged Austrian firms, 293 were approached (randomized) to have an energy efficiency audit conducted with us. A total of 121 decided to work with us. Firms had to pay the expenses on a market price basis. Competition was high, usually several auditors offered their service to one firm. Non-response bias is ruled out as all firms were obliged by law to perform an EE-audit. We checked the distribution of revenue and energy consumption in our sample for the two sectors 'process' and 'buildings', (fuels for transport weexcluded) with no evidence of systematic inhomogeneity or skewedness within or between the groups. Outliers such as energy service companies and an airline were excluded (for both, the data is not representative due to electricity grid losses counting as energy demand, and in the case of airlines, consumption is distorted as only fuel taken up in Austria is counted no matter how long the trip). Hence, out of the total of 293 firms, 51 complete datasets could be extracted, and 45 were taken into account (after exclusion of the mentioned outliers).

We do not consider the effect of high discounting, observed by Jaffe et al. (2003), in firms as a barrier itself but as an ex post effect often wrongly identified as such since it is a means of measuring the ceteris non paribus. To the contrary, we conjecture that the perceived implementation risk of EEMs is one factor contained in these asserted discount rates.

\section{Empirical data}

We measured energy savings bottom up for each measure. All the data was collected by the authors themselves from the firms directly or their respective energy service providers. Both the savings potential and realized savings were related to the total energy demand of the respective firm (excluding fuels for transportation) for normalization as firms' energy consumption varied 
Table 1 Assessment of the measurement model

\begin{tabular}{llll}
\hline Item & Mean & St. dev. & Share of sample** (\%) \\
\hline Firms revenue (M€) & 2671 & 15,453 & - \\
Energy consumption (GWh) & 41.5 & 41.8 & - \\
Process consumption* (\%) & 54.2 & 43.0 & - \\
Buildings cons.* (\%) & 32.7 & 39.0 & - \\
Energy efficiency potential* (\%) & 11.1 & 10.6 & - \\
Realized savings* (\%) & 2.3 & 2.6 & 64.4 \\
EEM maturity level (eq. to 1-risk)*** & 0.70 & 0.14 & 46.7 \\
Any MS implemented & - & - & 28.9 \\
Energy or environment. MS in pl. & - & - & 71.1 \\
External audit performed & - & - & 53.3 \\
Sector: Manufacturing & - & - & 44.4 \\
Sector: Services & - & - & 2.2 \\
Sector: Construction & - & & \\
\hline
\end{tabular}

*Per cent values in relation to total energy end use excluding fuels (GWh)

**Per cent of sample size (45)

$* * *$ Data available for $n=28$, points scale normalized to 1

widely (from 0.9 to $173 \mathrm{GWh}$ annually) after excluding the outliers.

Within this data, firms with MS and the control group with external audits were represented as dummy variables. Both ISO 50001 (energy) and ISO 14001 (environmental) MS focus on energy efficiency improvements and prescribe a detailed process to identify potentials, develop them into projects, manage energy investment decisions and carry out and monitor projects as outlined above. In the control group where firms performed external audits, this process was outsourced to a service provider up until the decision process. In the case of the environmental MS ISO 14001, the priority of energy efficiency as part of the gross environmental impact was chosen by the company. In all companies with environmental MS, energy savings had a high priority.

In the control group, firms either did not have any certified management system implemented or had a non-energy-related one, e.g. quality MS (ISO 9001), or health and safety MS (ISO 42001). For control purposes, the ones with any non-energy-related MS were identified separately. Here, it has to be added that the energy intensity of these firms was controlled for in the form of (manufacturing) process energy demand. None of the firms' energy costs exceeded $3 \%$ of total costs (apart from the excluded outliers which were energy service companies and one airline). Process energy demand can also be seen as a proxy for potential in-house technical competence since the manufacturing firms mostly had technical staff in house to maintain facilities.

One further observation from Table 2 is that manufacturing firms or firms with a higher share of process energy consumption were significantly more likely to have a MS in place.

Paradoxical as it may seem that a certificate is needed to act economically, the wide adoption in certain industries (e.g. car manufacturing in Europe) of environmental and energy management systems is a clear sign that the presented insight (Hypothesis 1) has been found there (Bonacina et al., 2015). While our work provides a strong case for management systems reducing market, behavioural and institutional efficiency barriers, our empirical work cannot give insight which of these specifically is lowered by how much. This interesting question opens further research opportunities. 


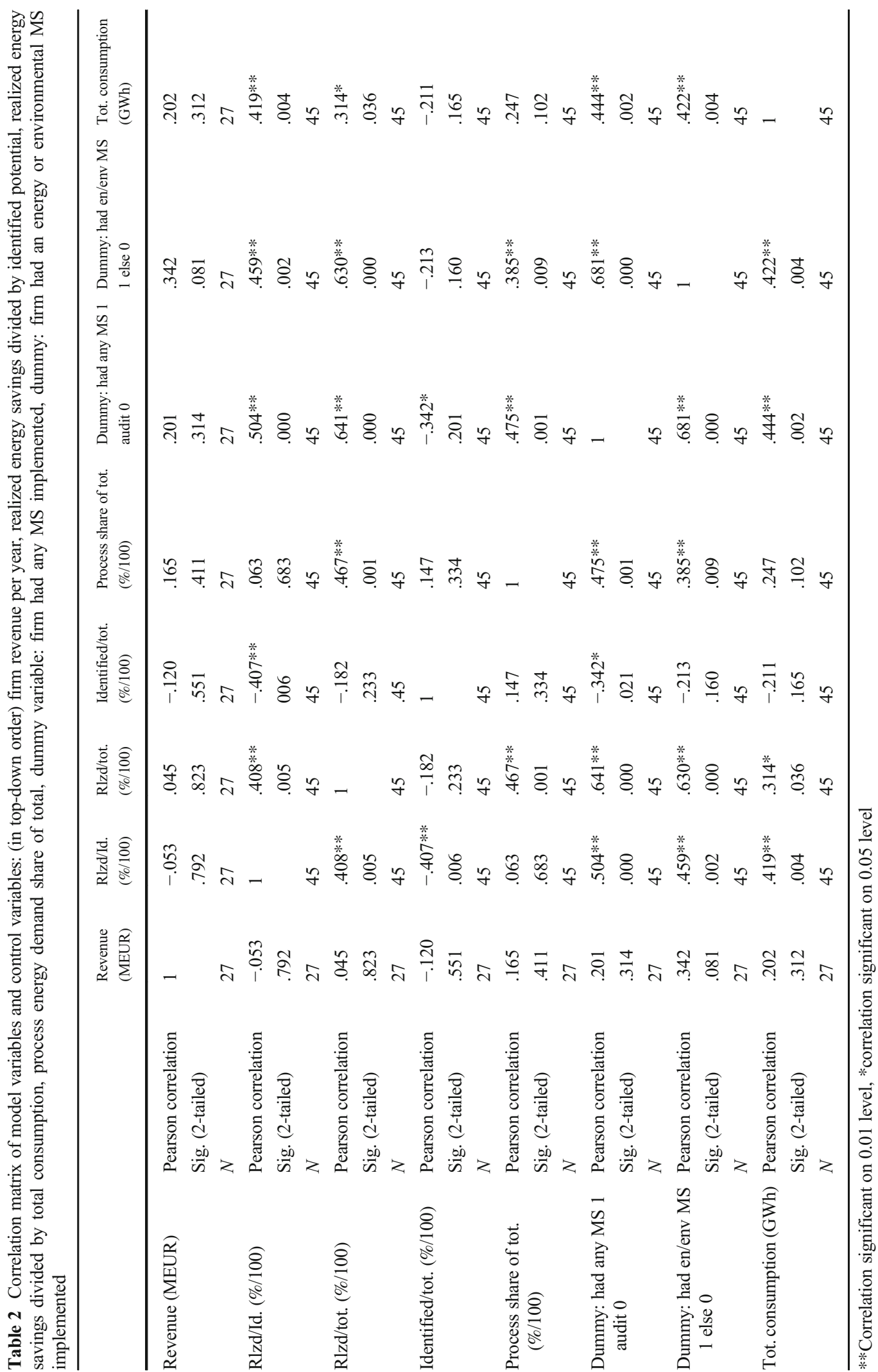




\section{Results and discussion}

We find that firms with MS in place increased energy efficiency measure implementation by $165 \%$ compared to the control group. This effect was measured in $\mathrm{kWh}$ saved per year originating from implemented EEM bottom up. That is, for each EEM, the energy saving effect was measured or calculated in terms of an expert opinion. In order to compare the effect between firms, this amount of energy was divided by the respective firms' total energy consumption, excluding transport for normalization. The detailed methodology is described in the 'Methodology' section. From this increase in EEMs implemented, we find support for Hypothesis 1. This effect is depicted in the distribution presented in Fig. 1 and 2 summarized in Table 3.

The increase of $165 \%$ of implemented savings measures in terms of kWh saved clearly stands out significantly in our empirical results. These higher conservation efforts in firms with MS in place mainly result from better
Table 3 Results of energy efficiency measure implementation compared with management style

Firms' management style Implemented e-eff savings* (\% of total demand)

No certified MS (control group) 1.7

Non-energy MS implemented 2.3

Energy or environmental MS $\quad 4.5$ implemented

*(GWh saved per anno by 2014 or 2015 implemented measures per GWh of total consumption, excluding transportation fuels)

organized energy management processes. Note that this does not mean that firms' overall energy consumption decreased by as much, as savings are assessed bottom up, and hence substitution and rebound effects cannot be excluded in the aggregate. Specifically, several firms in the sample increased output in the observed period, thereby increasing their overall energy consumption. If this had an effect on the considered EEM, it was corrected for by the base line adjustment described in the 'Methodology' section.
Fig. 1 Implemented energy savings versus management style
Firms' Realized Energy Savings vs. MS Style

amount of energy saved per firm normalized by total consumption

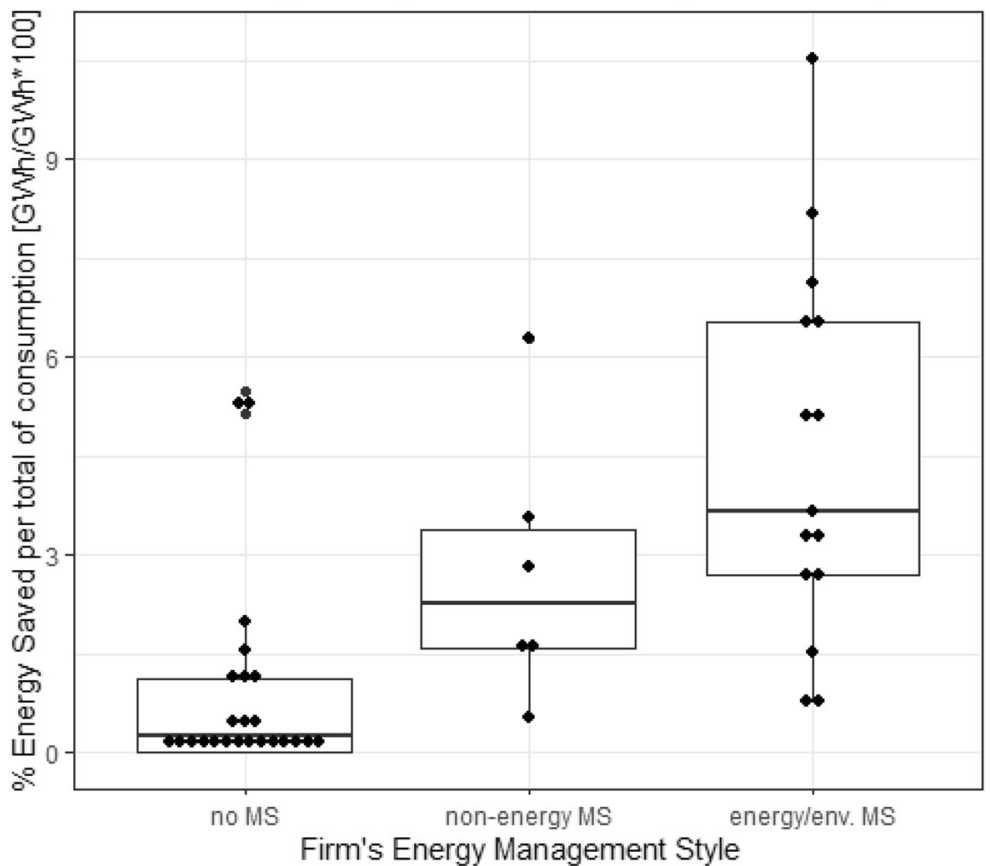

Source: own depiction 
A $t$-test within the MS group of firms having any MS in place versus those with only energy or environmental MS resulted in a $p$-value of 0.26 . Therefore, a distinction of which MS type is most effective cannot be drawn. From the significant difference in means of our two main groups, we conclude that firms focusing on good management practice implement more EEMs than ones with business-asusual energy management, thereby supporting Hypothesis 1 and providing further support for good management practice increasing a firms' profitability (Bloom and Van Reenen, 2010).

Further results can be seen from the correlation matrix in Table 2. Interesting there is the significant and high anti-correlation of identified efficiency potential versus implemented EEMs. We identify two main drivers for this paradox: first, firms with a MS in place have already harvested the 'low-hanging fruits' which an external auditor may find. Second, the filter for feasible measures is more refined in firms with a MS system in place. This was demonstrated by firms' energy managers' given reasons as to why implementation was not performed (yet) for most EEMs not implemented.

The respective medians are for firms with no MS $14.3 \%$, any MS $7.3 \%$ and an energy or environmental MS $7.8 \%$.

The higher the process share of energy consumption, the higher the likelihood of the firm having a MS in place and the more EEMs were implemented.

Contrary to expectations, the measure for implementation risk, or 'EEM maturity' as it was posed in the field study (which is its inverse), is not significantly correlated to EEM implementations. But, if controlled for the management style in place, a significant effect of this risk could be observed, as shown in Fig. 3. The results of the corresponding regressions and ANOVA are given in Appendix Table 5. Two factors were regressed on EEM implementation: project maturity, i.e. perceived risk, and management style, the ladder showing a significant effect. We found that firms with an energy or environmental MS in place raised energy efficiency by $165 \%$ compared to firms with no specific energy management processes. An ANOVA calculation of both regressions resulted in a significant interaction term of management style and perceived risk.
From these results, we conclude that the management style indeed has an explaining role in how much EEMs are implemented. Also, implementation of MS serves as a mediator to perceived implementation risk. That is, we found that in firms with MS in place, the more thoroughly EEMs were worked out, the more were implemented. For firms with usual management practices, no effect of this risk measure could be identified. Hypothesis 2 therefore is supported by the data.

The implementation and maintenance of MS pose costs for the firm. We found that most firms employ external advisories in the initial MS implementation phase in addition to the necessary external certification agents. These external costs were in most cases exceeded by the internal personnel costs for setting up the MS. Since no firm in the sample hired an additional full time energy manager, these labour costs are often perceived as opportunity costs by personnel. The economic benefit of MS' higher energy savings has to be confronted with all these implementation costs. In order to address whether MS are cost efficient for firms including these hidden costs, we compared them with the surplus generated by the implemented EEMs after accounting for each EEMs corresponding investment cost (if there were some). The highest costs occur in the initial MS implementation phase (lasting typically 6 to 12 months) with a median in our sample of EUR 34,000 (st. dev. EUR 25,000). After that, yearly 'recertification' and internal personnel costs are in the median of our sample EUR 17,000 (st. dev. 9.400), or 300 personnel-hours. These costs have to be covered by the EEMs in excess to their specific implementation costs. As a method for economic assessment, we chose the payback period of the MS costs, as no lifetime can be attributed to a management practice.

This analysis resulted in an average payback time of 3.7 years. In regard of $72 \%$ of firms having MS implemented for a longer time than that and comparing with the duration of the 16-year EU energy efficiency plan (2014 to 2030), we conclude that MS are a highly costeffective means of energy efficiency management. We therefore conclude that Hypothesis 3 is supported. That is: an energy or environmental management system is earning a firm money. 
Fig. 2 Identified economic e-eff savings potential versus management style

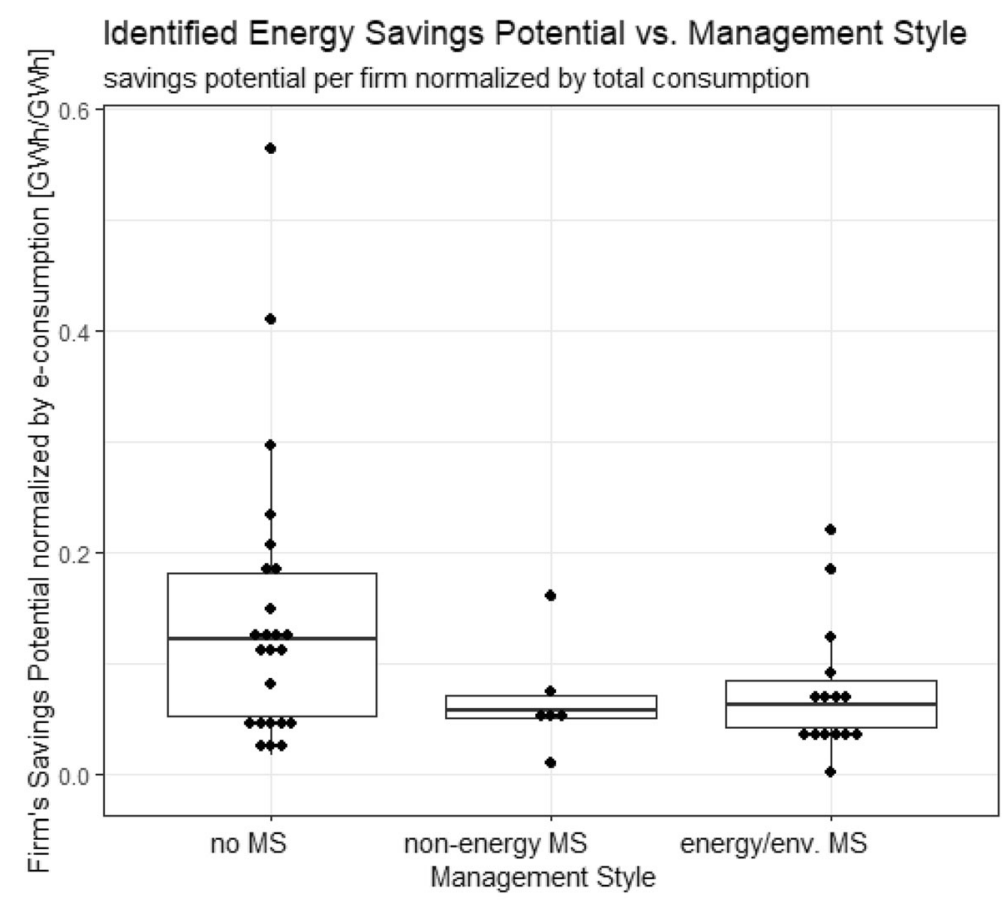

source: own depiction

Implemented Measures vs. Maturity and Management-Style

by amount of energy saved per firm, normalized by total of firms' consumption [GWh/GWh]

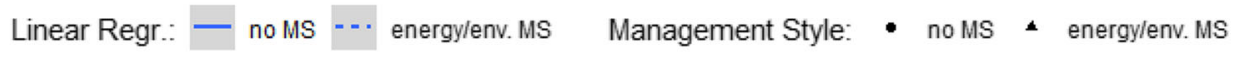

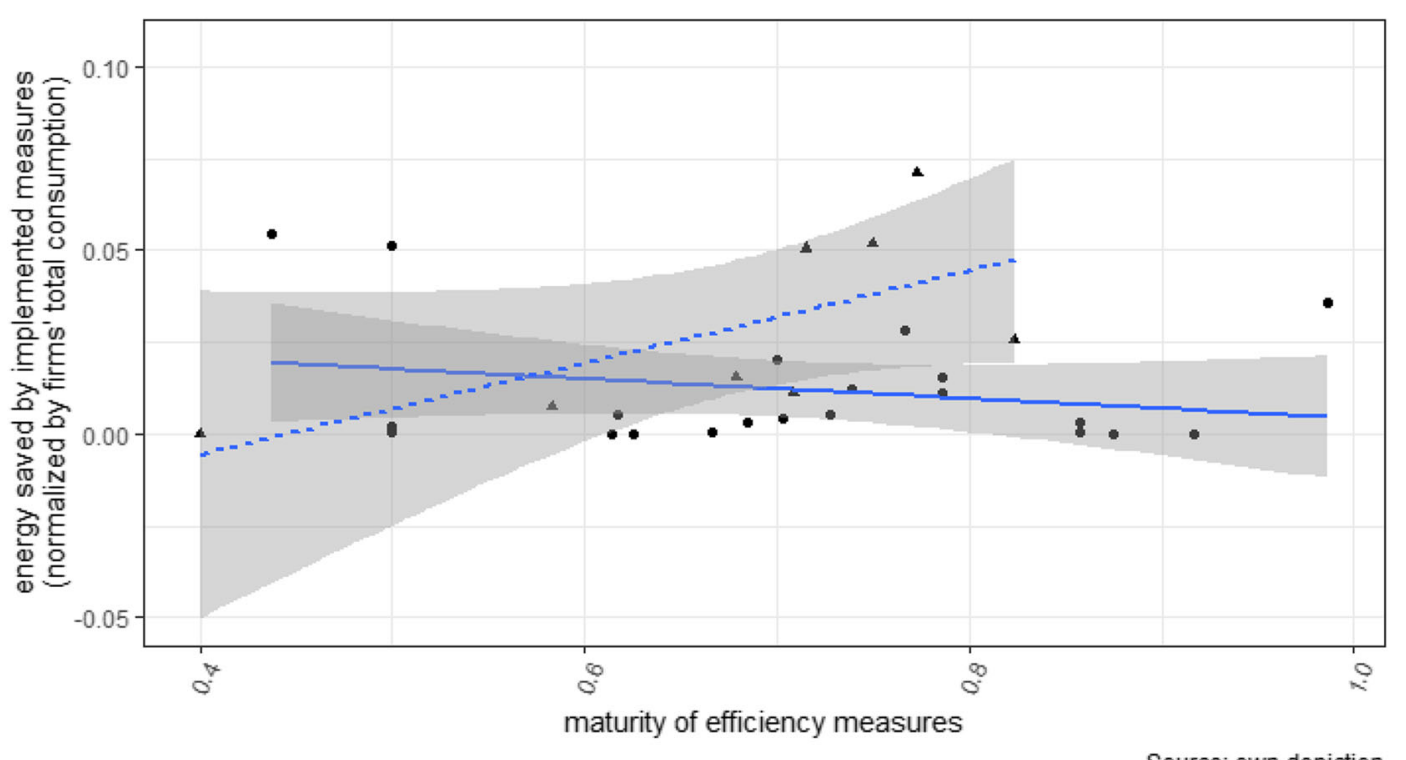

Fig. 3 Intersecting regressions of perceived risk on energy savings, grouped by management style 


\section{Conclusions}

We found that firms having certified energy or environmental management systems (according to ISO 50001 or ISO 14001) in place do increase their energy efficiency measure implementation by $165 \%$ compared to firms employing business-as-usual energy management. This higher EEM implementation rate supports our main hypothesis that management systems lower several barriers for energy efficiency. We conclude that we have identified and found empirical support for an economic and effective means of overcoming the efficiency gap in firms.

This article extends the panel data analysis presented by Paramonova et al. (2015). That is, management systems act as a driver for EEM implementation, supporting the claim of Paramonova et al. (2015) and adding a driver to the list in Rohdin and Thollander (2006). In aggregate, the 49 firms in our sample consumed $1865 \mathrm{GWh}$ a year and realized savings of 58 $\mathrm{GWh}$, that is $3.1 \%$ of their total consumption. The aggregated efficiency potential is $166 \mathrm{GWh}$ or $8.9 \%$ of firms' total consumption (excluding fuels for transportation). These results compare well with Paramonova and Thollander (2016) who worked on data derived from firms applying a more stringent payback filter. Previous research on barriers to energy efficiency has mostly been revolving around case studies where a few studies, e.g. Schleich and Gruber (2008), extend the scope and perform a survey. Similarly, the studies on energy management in industry (e.g. Backlund et al. (2012a, 2012b)) have so far been mainly conducted via surveys (e.g. Lawrence et al. (2019), or those reviewed by Jeffers and Lee (2019)) or case studies only. Therefore, only limited inference on the aggregate could be obtained so far. The current study thus makes a major contribution by adding empirical results on the impact of MS in firms. We present a diligent bottom-up approach which is the unique strength of this study since, as to the best of the authors' knowledge, no work exists that captures a comparable scope of industries and at the same time the presented depth of externally audited bottom-up data on energy efficiency measures, using a control group and showing that management systems in fact reduce barriers to energy efficiency.

We provided evidence that the perceived risk associated with the implementation of EEMs represents an explanatory factor as to why some EEMs were not implemented, supporting the findings of Cooremans and Schönenberger (2019). Which factors of this perceived risk exactly are reduced as a barrier could not be explained, posing potential for further research.

From our finding of MS being an effective means to increase production efficiency in one input (energy), four implications can be drawn: first: as argued by van der Linde and Porter (1995), streamlining production processes is not automatically performed, but an incentive scheme for economic actions must be provided. We present evidence that an energy or environmental MS does provide such an incentive scheme. Second, from the fact that firms featuring other types of MS (nonenergy-related ones) increased their EEM implementation, we infer that in general a structured decisionmaking process provides for a significant improvement in conservation efforts, as conjectured by Trianni et al. (2016). Third, from the variance of EEM implementation in the control group (with no MS in place), we conclude that certification of MS is not the relevant driver effectiveness but the quality of implementing good management practice is. Fourth, reputational benefits aside, a management system is an effective method for firms to increase their competitive advantage by lowering their cost base. We show that MS are a highly economic instrument to foster energy efficiency in firms with a cost-benefit breakeven period of 3.7 years after implementation, as has been postulated by Bergmann et al. (2017).

The apparent policy implication is to (further) encourage the implementation of energy and environmental management systems in 'large' firms, that is firms with more than 250 employees or more than 50M EUR in revenue as covered by our sample. Whether this holds true for small- and medium-sized enterprises is open to further research. Furthermore, putting into context firms' corporate environmental strategy and sustainability claims would be interesting with respect to identifying drivers for EEM implementation.

The take away from this study is that energy and environmental management systems increase firms' productivity, reduce their ecological impact, and thereby are highly beneficial both to their financial bottom line and to society. 
Acknowledgements We thank five reviewers who provided valuable feedback which improved this work greatly. All errors are the author's own.

Funding Open access funding provided by University of Vienna.

\section{Declarations}

Conflict of interest The author holds the position of managing director of the firm performing both energy audits and assisting firms in implementing MS. It is in the interest if his firm that e-eff projects are implemented (disregarding the client's management style) as planning these is part of its business.

\section{Appendix 1. Audit methodology}

Each identified measure was not only quantitatively assessed but also risk and uncertainties were taken into account by two of the four criteria 'organizational effort of implementation' and 'maturity of considerations'. The former representing the risk of production disruptions, probable product quality standard uncertainty, the ladder the depth of planning put into the measure.

Table 4 Assessment of e-eff potentials identified in the audits

\begin{tabular}{|c|c|c|c|c|}
\hline Criteria & 1 point & 2 points & 3 points & Weight \\
\hline $\begin{array}{l}\text { Economic feasibility } \\
\text { ROI [W] }\end{array}$ & $>6$ & $3-6$ & $0-3$ & 3 \\
\hline $\begin{array}{l}\text { Organizational effort of } \\
\text { implementation }[\mathrm{O}]\end{array}$ & $\begin{array}{l}\text { High: risk of prod. } \\
\text { disruption/quality issues }\end{array}$ & $\begin{array}{l}\text { Medium: possible prod. } \\
\text { disruption, no Q-issues }\end{array}$ & Low: no disruption, no Q-issues & 3 \\
\hline Maturity of EEM [A] & $\begin{array}{l}\text { Low: idea of the ext. } \\
\text { auditor }\end{array}$ & $\begin{array}{l}\text { Medium: idea was endorsed } \\
\text { by techn. staff }\end{array}$ & $\begin{array}{l}\text { High: worked out idea of int'l staff or } \\
\text { very simple implementation }\end{array}$ & 2 \\
\hline $\begin{array}{l}\text { Energy saving potential } \\
\quad \text { (absolute) }[\mathrm{E}]\end{array}$ & $<0.05 \%$ & 0.05 to $1 \%$ & $>1 \%$ of total E- consumption & 1 \\
\hline
\end{tabular}

All measures received a weighted grading according to

$P R Z=[W] \times 3+[O] \times 3+[A] \times 2+[E] \times 1$ where measures with zero points in one of the four categories were excluded. An example of such measures, their grading and evaluation is given in Table 6 .

Table 5 Regressions and ANOVA for MS style as mediator of EEM implementation

\begin{tabular}{|c|c|c|c|c|}
\hline Item & Estimate & Std. err. & $t$-value & $\operatorname{Pr}(>|t|)$ \\
\hline \multicolumn{5}{|l|}{$\begin{array}{l}\text { Regressions maturity of EEM on EEM } \\
\text { implementation (1) }\end{array}$} \\
\hline Intercept & 0.0157 & 0.0199 & 0.790 & 0.436 \\
\hline EEM maturity (matur) & 0.0016 & 0.0278 & 0.057 & 0.955 \\
\hline \multicolumn{5}{|l|}{ MS style on EEM implementation (2) } \\
\hline Intercept & 0.0125 & 0.0045 & 2.789 & $0.00785^{* *}$ \\
\hline MS style (env_energyMS1) & 0.0266 & 0.0071 & 3.748 & $0.00053 * * *$ \\
\hline \multicolumn{5}{|c|}{ Interaction of mgmt.-style and EEM maturity (3) } \\
\hline Intercept & 0.031 & 0.019 & 1.602 & 0.12 \\
\hline Management style (env_energyMS1) & -0.087 & 0.040 & -2.170 & $0.04 *$ \\
\hline EEM maturity (matur) & -0.027 & 0.027 & -0.999 & 0.33 \\
\hline Interaction (env_enrrgyMS1):(matur) & 0.152 & 0.057 & 2.65 & $0.014 *$ \\
\hline ANOVA (two way) ${ }^{1}$ & RSS & Sum of Sq. & $F$ & $\operatorname{Pr}(>F)$ \\
\hline$(1)<->(3)$ & 0.00796 & 0.00395 & 6.2 & $0.0065^{* *}$ \\
\hline$(2)<->(3)$ & 0.00796 & 0.00226 & 3.54 & $0.044 *$ \\
\hline
\end{tabular}

Significance codes: ‘***’ $0.001^{\text {' } * * ’} 0.01^{\text {‘*’ }} 0.05$; $^{1}$ for ANOVA same dataset of $n=28$ in all models 
Table 6 Exemplary e-eff measures

\begin{tabular}{|c|c|c|c|c|c|c|c|c|c|c|c|c|}
\hline Rank & Measure & $\begin{array}{l}\text { Payback } \\
\text { period }\end{array}$ & $\begin{array}{l}\text { Organizational } \\
\text { effort }\end{array}$ & Maturity & $\begin{array}{l}\text { Saving } \\
\text { potential }\end{array}$ & $\begin{array}{l}\text { Priority } \\
\text { number }\end{array}$ & $\begin{array}{l}\text { Energy } \\
\text { saving } \\
\text { potential } \\
(\mathrm{kWh} / \mathrm{a})\end{array}$ & $\begin{array}{l}\text { First } \\
\text { cost* } \\
(€)\end{array}$ & $\begin{array}{l}\text { Capital } \\
\text { cost** } \\
(€ / a)\end{array}$ & $\begin{array}{l}\text { Energy } \\
\text { cost } \\
\text { saving } \\
(€ / a)\end{array}$ & $\begin{array}{l}\text { Payback } \\
\text { period*** } \\
\text { (a) }\end{array}$ & $\begin{array}{l}\text { RIO } \\
\text { (\%p.a.) }\end{array}$ \\
\hline 1 & $\begin{array}{l}\text { Lamp replacement } \\
\text { HQL } 450 \mathrm{~W}->120 \mathrm{~W} \\
\text { LED } 50 \text { lamps }\end{array}$ & 3 & 3 & 3 & 3 & 27 & 74,300 & 18,450 & 799 & 7400 & 2.80 & 1.35 \\
\hline 2 & $\begin{array}{l}\text { Energy monitoring: } \\
\text { electricity and gas on } \\
\text { building level }\end{array}$ & 3 & 3 & 2 & 3 & 25 & 112,500 & 14,000 & 606 & 8400 & 1.80 & 2.04 \\
\hline 3 & $\begin{array}{l}\text { Compressed air: } \\
\text { shutdown during } \\
\text { non-operation time }\end{array}$ & 3 & 2 & 2 & 3 & 24 & 56,500 & 700 & 85 & 5700 & 0.12 & 1.03 \\
\hline 4 & $\begin{array}{l}\text { Compressed air } \\
\text { leakage } \\
\text { measurement and } \\
\text { elimination }\end{array}$ & 3 & 3 & 3 & 2 & 24 & 25,900 & 2000 & 87 & 2600 & 0.80 & 0.47 \\
\hline
\end{tabular}

\section{Appendix 2. Aggregated dataset}

The following table provides the dataset. Extreme outliers (energy service companies and an airline) are removed, hence the missing IDs. Used revenue data had to be excluded due to non-disclosure agreements.

The following variables were obtained for the dataset:

Firm ID; Revenue [M€]; implementation of which norm (implement_norm); has had MS before 2014 (hashad_MS); intern. / external audit (int_audt1_ext0); e-Consumption buildings [GWh] (cnsmptn_bldgsGWh); E-Consumption processes[GWh] (cnsmptn_procGWh); process consumption out of total [1] (przt_process_of_tot).; e-Consumption transport [GWh] (cnsmpt_trnspt); total energy consumption 2014 [GWh] (totl_econsumpt2014GWh) ; savings potential identified 2015 [GWh] (svngs-pot-identfd2015); potential out of total (przt_potential_of_total); realized savings 2014/15 [GWh] (rlzd_svings2015); realized savings out of total [1] (przt_rlzd_per_tot); realized savings out of identified [1] (przt_rlzd_of_idntfd); coded variables [1/0]: any MS 1 , Audit 0 ; only env./ energy MS 1; has-had any MS 1, Audit 0; hashad only env./energy MS;

Data on implementation costs of MS is available upon request but cannot be made publicly available. 


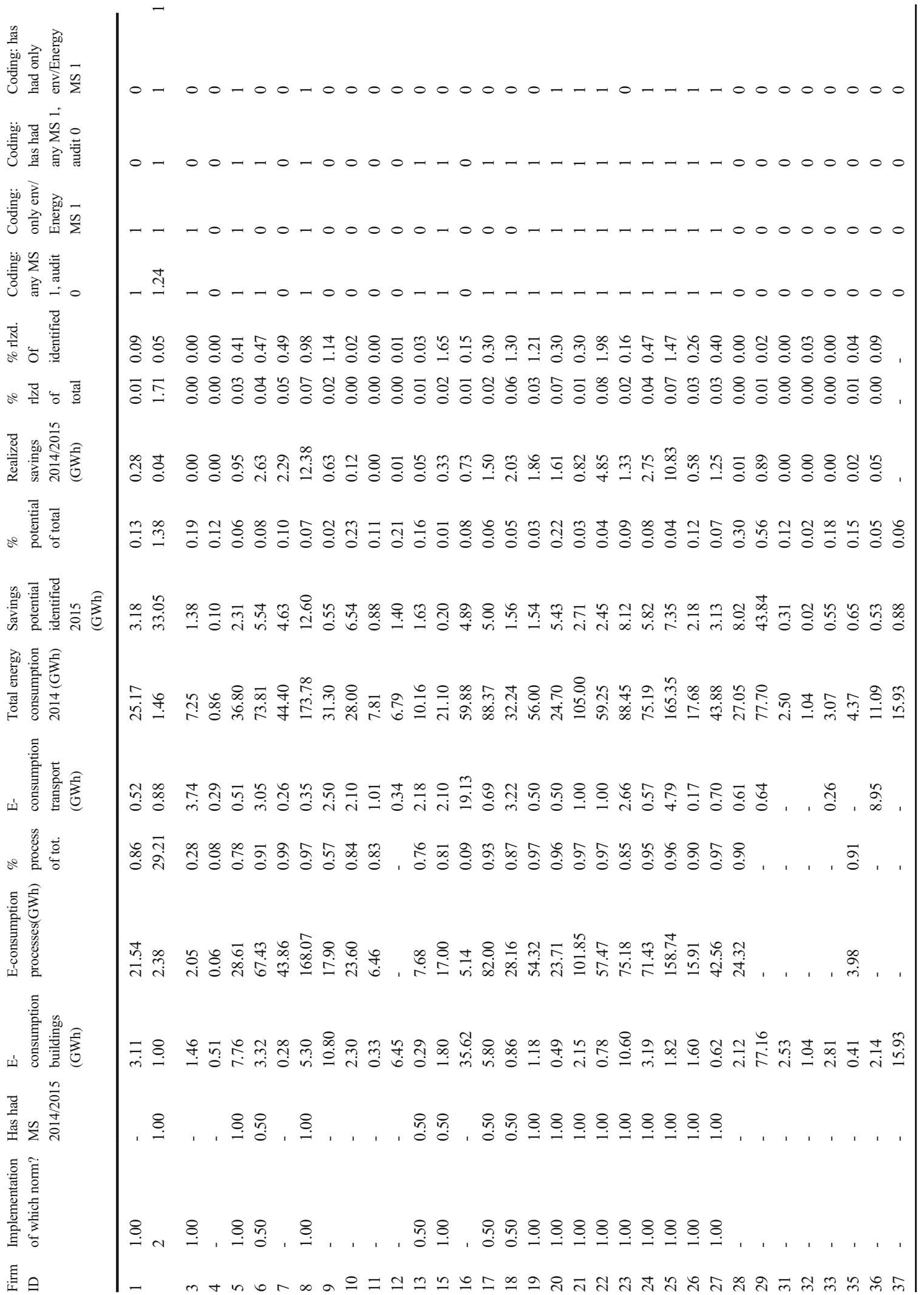




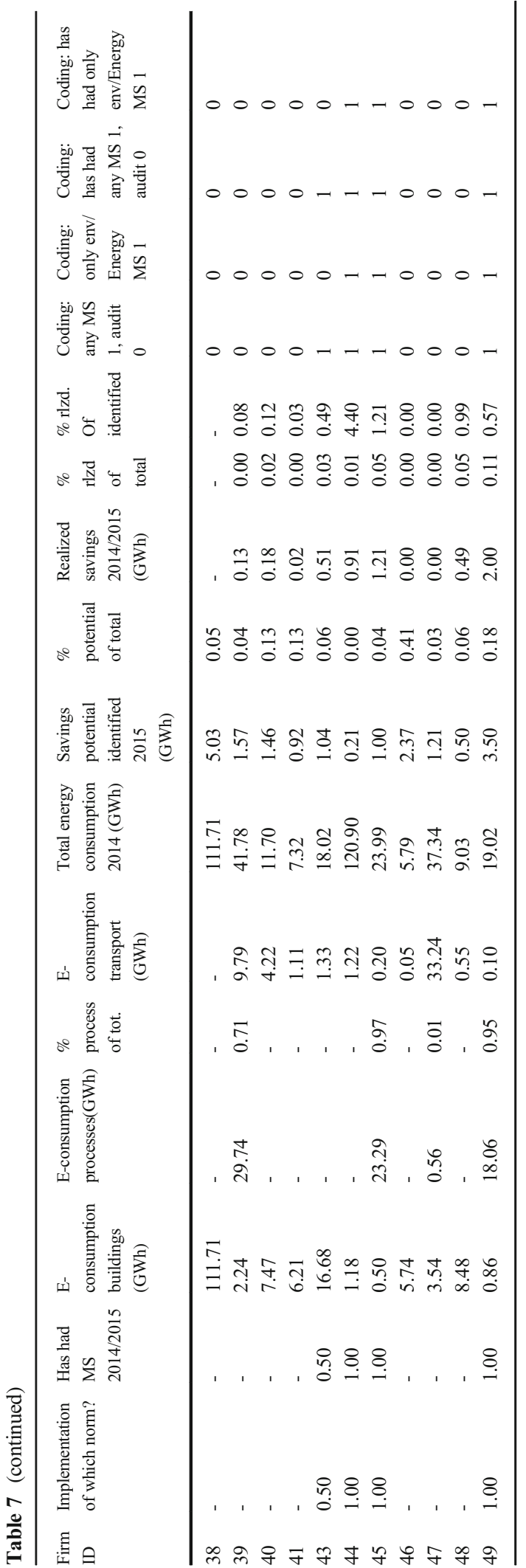

Open Access This article is licensed under a Creative Commons Attribution 4.0 International License, which permits use, sharing, adaptation, distribution and reproduction in any medium or format, as long as you give appropriate credit to the original author(s) and the source, provide a link to the Creative Commons licence, and indicate if changes were made. The images or other third party material in this article are included in the article's Creative Commons licence, unless indicated otherwise in a credit line to the material. If material is not included in the article's Creative Commons licence and your intended use is not permitted by statutory regulation or exceeds the permitted use, you will need to obtain permission directly from the copyright holder. To view a copy of this licence, visit http://creativecommons.org/licenses/by/4.0/.

\section{References}

Anderson, S. T., \& Newell, R. G. (2004). Information programs for technology adoption: The case of energy-efficiency audits. Resource and Energy Economics, 26(1), 27-50. https://doi.org/10.1016/j.reseneeco.2003.07.001.

Backlund, S., Ottosson, M., \& Broberg, S. (2012a). Energy efficiency potentials and energy management practices in Swedish firms, (eceee), 669-677. https://doi.org/10.1016/j. enpol.2012.08.042.

Backlund, S., Thollander, P., Palm, J., \& Ottosson, M. (2012b). Extending the energy efficiency gap. Energy Policy, 51, 392 396. https://doi.org/10.1016/j.enpol.2012.08.042.

Bergmann, A., Rotzek, J. N., Wetzel, M., \& Guenther, E. (2017). Hang the low-hanging fruit even lower - Evidence that energy efficiency matters for corporate financial performance. Journal of Cleaner Production, 147, 66-74. https://doi. org/10.1016/j.jclepro.2017.01.074.

Bloom, N., \& Van Reenen, J. (2010). Why do management practices differ across firms and countries? Journal of Economic Perspectives, 24(1), 203-224. https://doi. org/10.1257/jep.24.1.203.

Bonacina, F., Corsini, A., De Propris, L., Marchegiani, A., \& Mori, F. (2015). Industrial energy management systems in Italy: State of the art and perspective. Energy Procedia, 82, 562-569. https://doi.org/10.1016/j.egypro.2015.11.871.

Chan, Yeen, and Ravi Kantamaneni. 2015. "Study on energy efficiency and energy saving potential in industry and on possible policy mechanisms." https://ec.europa. eu/energy/sites/ener/files/documents/151201 DG ENER Industrial EE study - final report_clean_stc.pdf.

Concepción López Fernández, M., \& Serrano-Bedia, M. A. (2007). Organizational consequences of implementing an ISO 14001 environmental management system: An empirical analysis. Organization and Environment, 20(4), 440-459. https://doi.org/10.1177/1086026607309388.

Cooremans, C. (2011). Make it strategic! Financial investment logic is not enough. Energy Efficiency, 4(4), 473-492. https://doi.org/10.1007/s12053-011-9125-7.

Cooremans, C. (2012). Investment in energy efficiency: Do the characteristics of investments matter? Energy Efficiency, 5(4), 497-518. https://doi.org/10.1007/s12053-012-9154-x. 
Cooremans, C., \& Schönenberger, A. (2019). Energy management: A key driver of energy-efficiency investment? Journal of Cleaner Production, 230, 264-275. https://doi. org/10.1016/j.jclepro.2019.04.333.

Decanio, S. J. (1998). The efficiency paradox: Bureaucratic and organizational barriers to profitable energy-saving investments. Energy Policy, 26(5), 441-454. https://doi. org/10.1016/S0301-4215(97)00152-3.

Eurepean Union. n.d. Directive 2012/27/EU of the European Parliament and of the Council on Energy Efficiency, Amending Directives 2009/125/EC.

European Union. 2014. "Energy efficiency and its contribution to energy security and the 2030 framework for climate and en ergy policy." http:// e c.europa . eu/energy/sites/ener/files/documents/2014_eec_ia_adopted part1_0.pdf.

Fawcett, T., Rosenow, J., \& Bertoldi, P. (2019). Energy efficiency obligation schemes: Their future in the EU. Energy Efficiency, 12(1), 57-71. https://doi.org/10.1007/s12053018-9657-1.

Fleiter, T., Gruber, E., Eichhammer, W., \& Worrell, E. (2012). The German energy audit program for firms-A cost-effective way to improve energy efficiency? Energy Efficiency, 5(4), 447-469. https://doi.org/10.1007/s12053-012-9157-7.

Gerarden, T., Newell, R. G., \& Stavins, R. N. (2015). Assessing the energy-efficiency gap. Ssrn, 55, 1486-1525. https://doi. org/10.1257/jel.20161360.

Granade, Hannah Choi Creyts, Jon Derkach, Anton Farese, Philip Nyquist, Scott Ostrowski, Ken. 2007. "Unlocking energy efficiency opportunities." https://www.mckinsey. c o m/ / m edia / m ckinsey/d ot com/client_ service/epng/pdfs/unlockingenergyefficiency/us_energy_efficiency_exc_summary.ashx.

H. Adensam, T. Bogner, S. Geissler, Maike Groß, Marcus Hofmann, Robert Krawinkler, Konstantin Kulterer, Christoph Ploiner, Stephan Renner, Günter Simader, Gregor Thenius, Herbert Tretter. 2013. "Methoden Zur Richtlinienkonformen Bewertung Der Zielerreichung G e m ä $\beta \quad$ En e rgie e f fizi e n z - Und Energiedienstleistungsrichtlinie 2006/32 /EG." https://www. monitoringstelle.at/fileadmin/i m at/pdf/Methodendokument_RK_AT_Okt13.pdf.

Hirst, E., \& Brown, M. (1990). Closing the efficiency gap: Barriers to the efficient use of energy. Resources, Conservation and Recycling, 3(4), 267-281. https://doi. org/10.1016/0921-3449(90)90023-W.

Howarth, R. B., \& Andersson, B. (1993). Market barriers to energy efficiency. Energy Economics, 15(4), 262-272. https://doi.org/10.1016/0140-9883(93)90016-K.

ISO. 2015. ISO 14001:2015 - International Standard Environmental Management Systems - Requirements with guidance for use. Vol. 2015.

ISO. 2011. ISO 50001:2015 International Standard Energy Management Systems - Requirements with guidance for use. ISO 2011 (C) Iec:2001. Vol. 2011.

Jaffe, A. B., Newell, R. G., \& Stavins, R. N. (2003). Technological change and the environment. In Handbook of environmental economics (Vol. 1, p. 1). https://doi.org/10.2139 /ssrn.252927.
Jaffe, A. B., Newell, R. G., \& Stavins, R. N. (2004). Economics of energy efficiency. Encyclopedia of Energy, 2, 79-90. https://doi.org/10.1016/b0-12-176480-x/00228-x.

Jaffe, A. B., \& Stavins, R. N. (1995). Dynamic incentives of environmental regulations: The effects of alternative policy instruments on technology diffusion. Journal of Environmental Economics and Management, 29(3), S43S63.

Jaffe, A. B., \& Stavins, R. N. (1994). The energy-efficiency gap what does it mean ? Energy Policy, 1994(22), 804-810.

Jeffers, J., \& Lee, M. J. (2019). Corporate culture as an implicit contract. SSRN Electronic Journal. https://doi.org/10.2139 /ssrn.3426060.

Johansson, M. T. (2015). Improved energy efficiency within the Swedish steel industry-The importance of energy management and networking. Energy Efficiency, 8(4), 713-744. https://doi.org/10.1007/s12053-014-9317-z.

Lawrence, A., Nehler, T., Andersson, E., Karlsson, M., \& Thollander, P. (2019). Drivers, barriers and success factors for energy management in the Swedish pulp and paper industry. Journal of Cleaner Production, 223, 67-82. https://doi.org/10.1016/j.jclepro.2019.03.143.

Linde, Claas van der., and Michael E Porter. 1995. "Green and competitive: Ending the stalemate." HARVARD BUSINESS REVIEW. Vol. 73. https://hbr.org/1995/09/green-andcompetitive-ending-the-stalemate.

Mahapatra, K., Alm, R., Hallgren, R., Bischoff, L., Tuglu, N., Kuai, L., Yang, Y., \& Umoru, I. (2018). A behavioral change-based approach to energy efficiency in a manufacturing plant. Energy Efficiency, 11(5), 1103-1116. https://doi. org/10.1007/s12053-017-9581-9.

Nolden, C., \& Sorrell, S. (2016). The UK market for energy service contracts in 2014-2015. Energy Efficiency, 9(6), 1405-1420. https://doi.org/10.1007/s12053-016-9430-2.

Pachauri, Rajendra K, Myles R Allen, Vicente R Barros, John Broome, Wolfgang Cramer, Renate Christ, John A Church, et al. 2014. "Climate change 2014: Synthesis report. Contribution of Working Groups I, II and III to the Fifth Assessment Report of the Intergovernmental Panel on Climate Change." IPCC. https://www.ipcc. ch/site/assets/uploads/2018/05/SYR_AR5_FINAL_full_ wcover.pdf.

Paramonova, S., \& Thollander, P. (2016). Ex-post impact and process evaluation of the Swedish energy audit policy programme for small and medium-sized enterprises. Journal of Cleaner Production, 135, 932-949. https://doi.org/10.1016/j. jclepro.2016.06.139.

Paramonova, S., Thollander, P., \& Ottosson, M. (2015). Quantifying the extended energy efficiency gap-evidence from Swedish electricity-intensive industries. Renewable and Sustainable Energy Reviews, 51, 472-483. https://doi. org/10.1016/j.rser.2015.06.012.

Rasmussen, J. (2017). The additional benefits of energy efficiency investments - A systematic literature review and a framework for categorisation. Energy Efficiency, 10(6), 14011418. https://doi.org/10.1007/s12053-017-9528-1.

Redmond, J., \& Walker, B. (2016). The value of energy audits for SMEs: An Australian example. Energy Efficiency, 9(5), 1053-1063. https://doi.org/10.1007/s12053-015-9409-4.

Rietbergen, M. G., Farla, J. C. M., \& Blok, K. (2002). Do agreements enhance energy efficiency improvement? Analysing 
the actual outcome of long-term agreements on industrial energy efficiency improvement in the Netherlands. Journal of Cleaner Production, 10(2), 153-163. https://doi. org/10.1016/S0959-6526(01)00035-X.

Rietbergen, M. G., Opstelten, I. J., \& Blok, K. (2017). Improving energy and carbon management in construction and civil engineering companies-Evaluating the impacts of the CO2 performance ladder. Energy Efficiency, 10(1), 55-79. https://doi.org/10.1007/s12053-016-9436-9.

Rohdin, P., \& Thollander, P. (2006). Barriers to and driving forces for energy efficiency in the non-energy intensive manufacturing industry in Sweden. Energy, 31(12), 1836-1844. https://doi.org/10.1016/j.energy.2005.10.010.

Schleich, J. (2009). Barriers to energy efficiency: A comparison across the German commercial and services sector. Ecological Economics, 68(7), 2150-2159. https://doi. org/10.1016/j.ecolecon.2009.02.008.

Schleich, J., \& Gruber, E. (2008). Beyond case studies: Barriers to energy efficiency in commerce and the services sector. Energy Economics, 30(2), 449-464. https://doi.org/10.1016 j.eneco.2006.08.004.

Schuch, Alfred, and Günter Simader. 2017. "Marktentwicklungen von Energieeffizienz- Maßnahmen, Energieaudits Und Anderen Energiedienstleistungen Gemäß $\S 24$ Abs . 2 Z 8 EEffG." https://www.monitoringstelle.at/fileadmin/i_m at/pdf/Markbeobachtung_Report_2017_1.pdf.

Schulze, M., Nehler, H., Ottosson, M., \& Thollander, P. (2016). Energy management in industry - A systematic review of previous findings and an integrative conceptual framework. Journal of Cleaner Production, 112, 3692-3708. https://doi. org/10.1016/j.jclepro.2015.06.060.

Solnørdal, M. T., \& Foss, L. (2018). Closing the energy efficiency gap-A systematic review of empirical articles on drivers to energy efficiency in manufacturing firms. Energies, 11(3). https://doi.org/10.3390/en11030518.
Sorrell, S., Mallett, A., \& Sheridan, N. (2011). Barriers to industrial energy efficiency: A literature review. Renewable Energy, 35(3), 1891-1901. https://doi.org/10.1016/S00142921(98)00047-6.

Sorrell, Steve, Eoin O’Malley, Joachim Schleich, and Scott Sue. 2004. "The economics of energy efficiency." In .

Sutherland, R. J. (1991). Market barriers to energy-efficiency investments. The Energy Journal, 12(3). https://doi. org/10.5547/issn0195-6574-ej-vol12-no3-3.

Thollander, P., \& Ottosson, M. (2008). An energy efficient Swedish pulp and paper industry - Exploring barriers to and driving forces for cost-effective energy efficiency investments. Energy Efficiency, 1(1), 21-34. https://doi. org/10.1007/s12053-007-9001-7.

Trianni, A., \& Cagno, E. (2012). Dealing with barriers to energy efficiency and SMEs: Some empirical evidences. Energy, 37(1), 494-504. https://doi.org/10.1016/j. energy.2011.11.005.

Trianni, A., Cagno, E., \& Farné, S. (2016). Barriers, drivers and decision-making process for industrial energy efficiency: A broad study among manufacturing small and medium-sized enterprises. Applied Energy, 162, 1537-1551. https://doi. org/10.1016/j.apenergy.2015.02.078.

Trianni, A., Cagno, E., Marchesani, F., \& Spallina, G. (2017). Classification of drivers for industrial energy efficiency and their effect on the barriers affecting the investment decisionmaking process. Energy Efficiency, 10(1), 199-215. https://doi.org/10.1007/s12053-016-9455-6.

Wirl, Franz. 1997. "The economics of conservation programs." The Economics of Conservation Programs, no. October. https://oi.org/10.1007/978-1-4615-6301-3.

Publisher's note Springer Nature remains neutral with regard to jurisdictional claims in published maps and institutional affiliations. 